\title{
Suspected Long-Term Population Increases in Common Eiders, Somateria mollissima, on the Mid-Labrador Coast, 1980, 1994, and 2006
}

\author{
KeIth G. ChaulK
}

Labrador Institute, Department of Biology, Memorial University of Newfoundland, PO Box 490, Station "B”, Happy ValleyGoose Bay, Newfoundland and Labrador A0P 1E0 Canada

Chaulk, Keith G. 2009. Suspected long-term population increases in Common Eiders, Somateria mollissima, on the midLabrador coast, 1980, 1994, and 2006. Canadian Field-Naturalist 123(4): 304-308.

Aerial surveys for adult male Common Eiders, Somateria mollissima, were flown on the Labrador coast during June 2006. This information was then compared with aerial counts of adult male Common Eiders collected in 1980 and 1994 . For each survey year, data were grouped and paired by coastal block and were analyzed for population trends. Overall, the observed counts of adult male Common Eiders increased by 244\% between 1980 and 2006. Much of this increase seemed to occur in the southern region of the study area.

Key Words: Common Eider, Somateria mollissima, aerial survey, population trends, Labrador.

In the last decade, declines in the populations of Common Eider (Somateria mollissima) have been documented in various regions of the north, such as Hudson Bay, the Beaufort Sea, and western Greenland (Robertson and Gilchrist 1998; Suydam et al. 2000; Merkel 2004). Factors identified as causing these declines include human disturbance, over-harvesting, and climatic events. However, not all Common Eider populations are decreasing. Christensen and Falk (2001) found evidence of population stability in northwest Greenland, and others have documented increases in Hudson Strait (Hipfner et al. 2002; Falardeau et al. 2003) and in the Gulf of St. Lawrence (Cotter and Rail 2007; Rail and Cotter 2007).

With respect to Labrador, from 1998 to 2003, Chaulk et al. (2005) documented average annual increases in Common Eider populations of 18\% (range 13-22\%). However, that study was limited in temporal and geographic scope, and thus the overall direction and extent of longer-term population trends for the region remained unclear. This study examines counts of adult male Common Eiders on the mid-Labrador coast over a 26-year period using data collected during three time periods, in 1980, 1994, and 2006.

\section{Study Area}

The study area, located in the sub-Arctic on the midLabrador coast, is approximately $19714 \mathrm{~km}^{2}$ (Figure 1) and contains 5296 islands and islets ranging in size from 0.01 to 7205.77 ha, with an average island size of 22.90 ha (unpublished data). All islands share similar environmental characteristics, such as a northern maritime climate and vegetation composed primarily of moss, lichen, forb, grass, and sedge. The region is considered to have a low Arctic oceanographic regime (Nettleship and Evans 1985) and is classified as a coastal barrens (Lopoukhine et al. 1978). Two subspecies of Common Eider occur in the study area: $S$. $m$. borealis occurs throughout, while the northern edge of the range of $S$. $m$. dresseri intersects the southern portion of the study area (Mendall 1980; Goudie et al. 2000; Chaulk et al. 2004). The line of demarcation between the two subspecies is not well established, and some have suggested that a hybridization zone occurs in the region of Groswater Bay (Mendall 1980), the center of which lies at about $54^{\circ} 20^{\prime}$ north latitude and is adjacent to the community of Rigolet (Figure 1).

\section{Methods}

From 6 to 24 June 2006, aerial surveys were flown on the mid-Labrador coast (Figure 1) using a twin engine Normandy Islander; flight altitudes ranged between 200 and $300 \mathrm{~m}$ Above Sea Level and air speeds ranged between 150 and $180 \mathrm{~km} / \mathrm{h}$; sea ice was absent from all survey areas. The 2006 surveys involved one observer/navigator, one rear observer, and one pilot. Data from 2006 were then compared to surveys conducted in 1980 and 1994 . The 1980 surveys (18 June to 20 July) were flown with one observer/navigator and one pilot (Lock 1986). The 1994 surveys (17 June to 8 July) used one observer/navigator, two rear observers, and one pilot (S. Gilliland, unpublished). In all cases, the pilot assisted with observations.

All coastal shorelines (mainland and island) within the study area (Figure 1) were surveyed in 1980, 1994, and 2006. The 1980 and 1994 surveys covered the entire coastline of Labrador (Lock 1986; Gilliland, unpublished), while the 2006 survey was about onethird the coverage of the previous surveys (Figure 1). All surveys started in the south and moved northwards.

In this paper, only data from the section of coast surveyed in all three years and highlighted in Figure 1 are reported. In 1980 and 1994, count data were recorded on paper maps and later compiled by coastal block (see below). In 2006, the United States Fish and Wildlife GPS Voice Survey Recording program (v. 3.1) was 


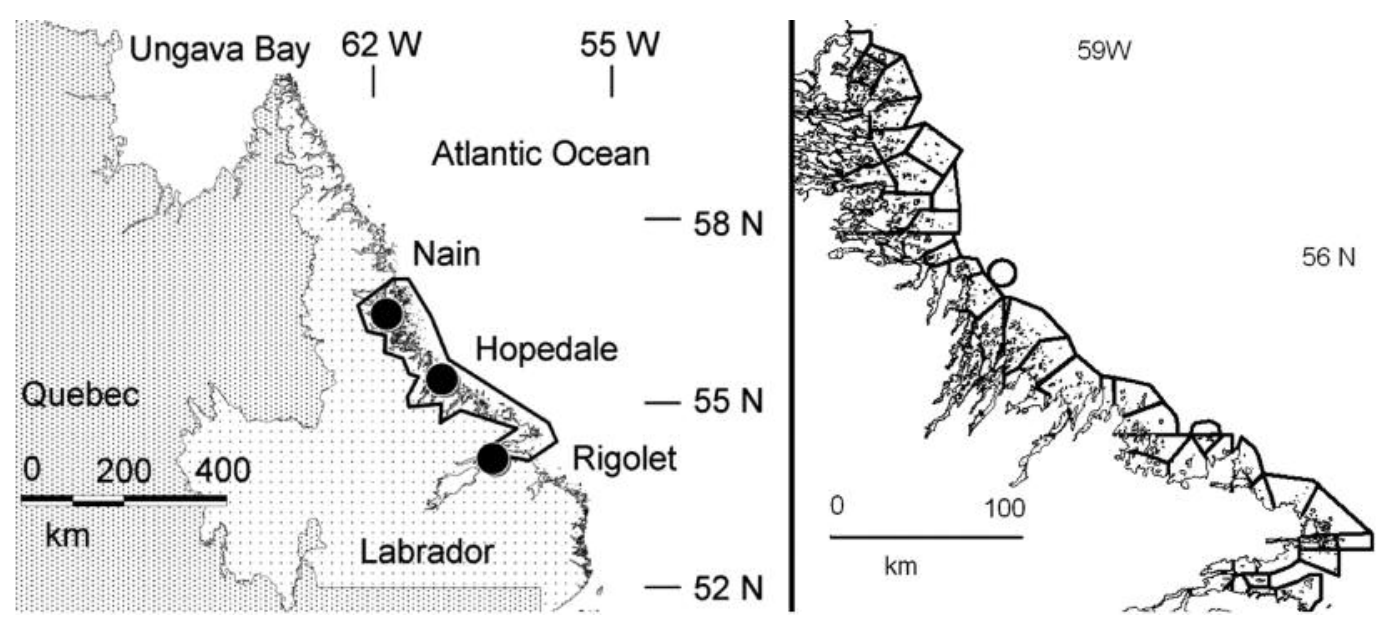

FIGURE 1. Location of the 2006 study area on the mid-Labrador coast. Left panel shows all of Labrador with the 2006 study area highlighted; right panel illustrates only the 2006 study area and the distribution of the 64 coastal blocks surveyed in all three years $(1980,1994$, and 2006).

Note: the 1980 and 1994 surveys included areas north and south of the blocks illustrated; however, only data from the 64 coastal blocks (shown in right panel) (surveyed in 1980, 1994, and 2006) are presented and analyzed in this paper.

used to record all observations (Chaulk and Turner 2007), which were subsequently compiled by coastal block.

To allow the data sets across years to be summarized and compared across years, all count data were compiled by coastal block, a grid system developed by the Canadian Wildlife Service to partition the Labrador coast into discrete survey units based on prominent landscape features (Gilliland, unpublished). For purposes of statistical testing, the same 64 blocks surveyed in 1980, 1994, and 2006 were "paired" and analyzed for trends (Figure 1). The average size of these 64 coastal blocks was $308 \mathrm{~km}^{2}(\mathrm{SD}=185.3)$.

Coastal blocks were then sorted from south to north by the geographic center, and adjacent coastal blocks were grouped into aggregate blocks. Each of the four resulting aggregate blocks was composed of 16 coastal blocks $(4 \times 16=64)$. The aggregate blocks were consecutively labelled $1,2,3,4$, with 1 being the most southerly and 4 the most northerly. The 95\% confidence interval for the mean was calculated for each aggregate block and plotted by survey year. This exercise was performed to illustrate regional and annual variations within the overall data set.

As the study team progressed northwards along the coast in 2006, approximately 20-30 nests were candled (Weller 1956) in each of the archipelagos of Rigolet, Hopedale and Nain to assess stage of incubation (Figure 1).

Throughout the paper, all reported \pm values are $1 \mathrm{SE}$ (except where noted). No data transformations were used, and non-parametric Friedman's test (predictors:
Year and Block ID) and pair-wise $t$-tests of the count data were conducted using Minitab version 14.1.

\section{Results}

Candling revealed that the 2006 survey occurred between the first and second week of nest initiation. In 2006, total adult male Common Eider counts were 17374 (number of flocks $=1733$, mean flock size $=$ $10.03 \pm 0.63$ ). Of these, 13014 (i.e., $74.9 \%$ ) adult male Common Eiders were associated with islands (number of flocks $=1332$, mean flock size $=9.77 \pm 0.69$ ), and approximately $80 \%$ of these were associated with islands smaller than 30 ha. The average number of adult males/island was $15.6 \pm 1.2$ (number of colonies $=834$ ).

The mean number of male Common Eiders per coastal block increased from a low of $111.3 \pm 17.2$ in 1980 to $271 \pm 41.3$ in 2006 (Table 1), a population increase of $244 \%$. Using a Friedman's test, counts were found to differ significantly by year $(P<0.001)$; pairwise $t$-tests indicated that 2006 counts were significantly higher than $1980(P<0.001)$. Interval plots revealed little change in counts across years in northern sections of the study area; these plots showed that most of the increases occurred in the southern portion of the study area (Figure 2).

\section{Discussion}

Based on informal interviews at the start of surveys, many local residents of Labrador stated that 2006 was an early spring, perhaps four weeks earlier than historical norms. Visual analyses of ice charts for the 
TABLE 1. Left panel summarizes observations of adult male Common Eiders on the mid-Labrador coast by survey year $(n=3)$ and aggregate block $(n=4)$. Right panel summarizes pair-wise $t$-tests by year.

\begin{tabular}{ccc|ccc}
\hline \hline Year & Total Count & Average Count (SE) & Years & $P$ & $t$-value \\
\hline 1980 & 7120 & $111.3(17.2)$ & 1980,1994 & 0.001 & -3.59 \\
1994 & 13994 & $218.7(39.5)$ & 1994,2006 & 0.109 & -1.62 \\
2006 & 17374 & $271.5(41.3)$ & 1980,2006 & 0.000 & -4.60 \\
\hline \hline
\end{tabular}

study area support this assessment and also suggest that 1980 and 1994 were similar with respect to the timing of spring ice break-up. First indications of major open water can be found on the ice charts of 22 June 1980, 19 June 1994, and 15 May 2006 (Canadian Ice Service Online Data 2010*).

Although the 1980 surveys did not report stage of incubation, the author indicates that the surveys commenced approximately 10-12 days after the start of laying (Lock 1986). Unfortunately, the 1994 surveys did not provide any information on the timing of nesting (Gilliland, unpublished). Based on estimated nest ages (eggs in 2006 were 7 to 14 days old), the timing of the 2006 surveys was similar to the 1980 surveys. It should be noted that both Lock and Gilliland initiated their surveys several hundred kilometres to the south and took up to one week to reach the point at which the 2006 surveys started. Adjusting for the overlapping study area (Figure 1), the 2006 surveys started approximately three calendar weeks earlier than surveys in 1980 and 1994.

However, even with the earlier survey start date and earlier spring conditions in 2006, I feel that, relative to breeding, the 2006 surveys were comparable to the 1980 surveys (i.e., within 10 days) (see discussion above of ice conditions and nest ages of all three surveys). However, owing to the absence of information on nest ages at the time of the 1994 surveys, it is not possible to state with rigor how all survey years compared with respect to the nesting period.

It is very likely that across-year environmental differences influenced the start of breeding in each of the survey years and that this would consequently affect observed counts, although the direction (resulting in higher or lower counts) of these effects, relative to survey year, remains unknown. If Common Eiders nested early in 2006 due to lack of ice, adult males may have started to disperse by the time of the survey, reducing the overall count. For example, it has previously been suggested that ice influences the nesting behaviour of eiders (Lack 1933; Ahlen and Andersson 1970; Quinlan and Lehnhausen 1982; Parker and Mehlum 1991; Chaulk et al. 2007), and male Common Eiders are known to disperse from breeding islands shortly after females begin nesting (Goudie et al. 2000).

Uneven observer effort is another factor that could have influenced comparison of count data across years (Caughley 1974). Laursen et al. (2008) found that detection rates were approximately $80 \%$ for species with densities of more than 10 individuals $/ \mathrm{km}^{2}$ and that observer effects are less pronounced in species that form large flocks. It should be noted that in 2006 the average was approximately 10 Common Eiders/ flock. Estimates of average flock size from other survey years were not reported, so at present this information is limited as an indicator of across-year detection rate(s). However, the 2006 flock size data could be useful comparison information in the event of future surveys. With this said, it is not clear how average flock size changes with population fluctuation. One might assume that flocks become larger as the population increases, but behavioural processes and availability of forage likely play a role in shaping the relationships between flock size and overall abundance.

As indicated in the methods, each survey year involved a different number of observers, with 1980 having the least (two), 2006 surveys having an intermediate number (three), and 1994 having the most (four). The effects that observer effort had on counts are unknown, but likely contributed to across-year differences. However, the direction (resulting in higher or lower counts) of these effects relative to each survey year also remains unknown.

Figure 2 depicts regional differences within the study area with respect to long-term population trends. Mean counts were relatively constant across years in the north, while southern sections showed larger acrossyear differences. Thus many of the suspected long-term increases seem to be driven by population processes in the southern portion of the study area. Within the study area, the southern section is thought to be a region of overlap and hybridization between the northern and southern subspecies of the Common Eider (Mendall 1980; Chaulk et al. 2004). It is possible that interactions between these two subspecies are influencing the overall apparent population growth.

It is true that this study suffers from several limitations with respect to the comparability of the data across years (observer effort, survey timing); however, in combination with findings presented by Chaulk et al. (2005) as well as anecdotal reports by local hunters, it seems to provide growing evidence that suggests that Common Eider populations on the mid-Labrador coast have grown since the early 1980s. The cause(s) of these apparent increases are unknown.

One explanation relates to changes in human land use during the breeding period as a result of the closure of coastal in-shore fisheries in the early 1990s. 


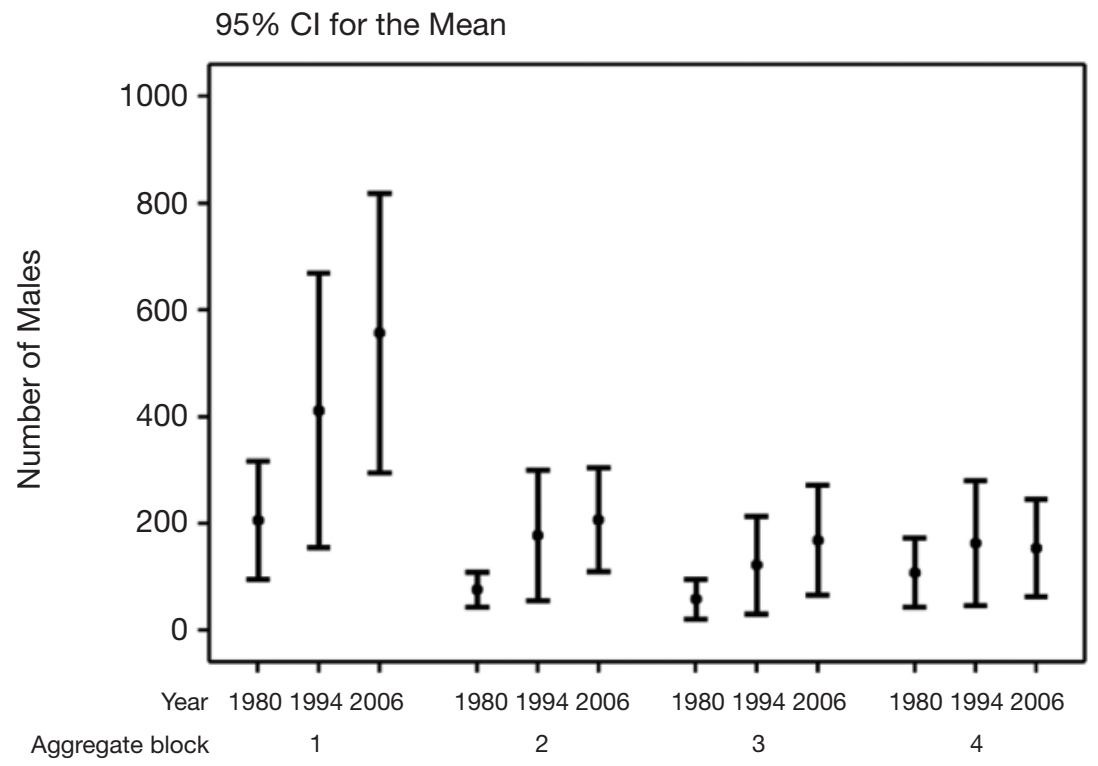

FIGURE 2. Interval plots of adult male Common Eider counts by aggregate block and year. Data means and 95\% confidence intervals are based on surveys conducted on the midLabrador coast in 1980, 1994, and 2006. Each aggregate block $(n=4)$ is composed of 16 adjacent coastal blocks. Aggregate blocks are labelled 1 to 4 and are ordered from south to north, where aggregate block 1 is the most southerly and 4 the most northerly.

Note: For purposes of graphing, aggregate blocks ( $n=4$; by 3 years) were used instead of coastal blocks $(n=64$; by 3 years $)$ in order to reduce data clutter.

For example, a reduction in fish offal may have had an impact on local gull populations, thereby decreasing gull predation on Common Eider nests (Gotmark 1989; Mawhinney et al. 1999). In addition, the closure of the in-shore fishery likely resulted in less disturbance of breeding colonies (Gotmark and Ahlund 1984; Laursen and Frikke 2008) by fishing boats, as well as possible reductions in egging and the harvest of adult birds.

Northland Associates (1986*) report that the mean household harvest of Common Eiders in 1980 by the Inuit communities of Hopedale was $52.9(n=21$ households) and Postville was 29.1 ( $n=21$ households). Felt and Natcher (in press) report that the mean household harvest of Common Eiders in the same communities in 2007 was 19.0 in Hopedale $(n=41$ households) and 9.0 in Postville ( $n=26$ households). Thus harvest levels in 2007 were lower than in 1980; it is unknown whether other communities in the study area reduced their harvest of Common Eiders over this period.

Other possible, albeit undocumented, explanations for apparent increases in counts of Common Eiders include hunter education and conservation awareness programs, habitat enhancement programs (i.e., nest shelter), and/or an amelioration of environmental conditions resulting from climate change. Education and nest shelter programs were initiated in Labrador in the mid-1990s, but assessments of their effect on populations of Common Eiders have not been widely reported. With respect to the regulation of migratory bird harvest, this region of Labrador continues to have a limited enforcement presence.

\section{Acknowledgments}

I thank Rene Geoffroy and Pierre Ryan for their help conducting the 2006 survey. Special acknowledgements to Scott Gilliland and Tony Lock for providing access to their earlier survey data, which made the trend analysis possible. Thanks to Jennifer Butler and Martha MacDonald for their editorial comments during manuscript preparation. Editorial comments provided by A. J. Erskine and an anonymous reviewer were also helpful in finalizing this manuscript. Brian Collins provided valuable advice on appropriate statistical methods. Funding for this project was provided by Environment Canada. 
Documents Cited (marked $*$ in text)

Canadian Ice Service Online Data. 2010. Canadian Ice Service, Government of Canada, Ottawa. http://ice-glaces. ec.gc.ca

Gilliland, S. Unpublished. Temporal and spatial patterns in abundance and distribution of common eiders along the coast of Labrador. Canadian Wildlife Service, St. John's Newfoundland and Labrador, Canada. 10 pages.

Northland Associates. 1986. Native Waterfowl Harvest in coastal Labrador. Supply and Services Canada Tender: KL 103-0-0398. St. John's, Newfoundland and Labrador. 77 pages.

\section{Literature Cited}

Ahlen, I., and A. Andersson. 1970. Breeding ecology of an eider population on Spitsbergen. Ornis Scandinavia 1: 83106.

Caughley, G. 1974. Bias in aerial surveys. Journal of Wildlife Management 38: 921-933.

Chaulk, K. G., and B. C. Turner. 2007. The timing of waterfowl arrival and dispersion during spring migration in Labrador. Northwestern Naturalist 14: 375-386.

Chaulk, K. G., G. J. Robertson, and W. A. Montevecchi. 2004. Regional and annual variability in common eider nesting ecology in Labrador. Polar Research 23: 121-130.

Chaulk, K. G., G. J. Robertson, B. T. Collins, W. A. Montevecchi, and B. C. Turner. 2005. Evidence of recent population increases in common eiders breeding in Labrador. Journal of Wildlife Management 69: 805-809.

Chaulk, K. G., G. J. Robertson, and W. A. Montevecchi. 2007. Landscape features and sea ice influence nesting eider abundance and dispersion. Canadian Journal of Zoology 85: 301-309.

Christensen, K. D., and K. Falk. 2001. Status of the Common Eider breeding in the municipality of Avanersuaq (Thule), northwest Greenland. Polar Research 20: 109-114.

Cotter, R., and J-F. Rail. 2007. Third census of seabird populations of the Gaspe Peninsula, Quebec, 2002. Canadian Field-Naturalist 121: 274-286.

Falardeau, G., J-F. Rail, S. Gilliland, and J-P. L. Savard. 2003. Breeding survey of common eiders along the west coast of Ungava Bay, in summer 2000, and a supplement on other nesting aquatic birds. Canadian Wildlife Service, Québec Region, Sainte-Foy. Technical Report Series Number 405.

Felt, L., and D. Natcher. In press. Settlement, subsistence and change among the Inuit of Nunatsiavut, Labrador. Chapter 7 in Patterns of Wild food Harvesting by the Labrador Inuit on the North Labrador Coast. Edited by D. Natcher, L. Felt and A. Procter. University of Manitoba Press, Winnipeg.

Gotmark, F. 1989. Costs and benefits to eiders nesting in gull colonies: a field experiment. Ornis Scandinavica 20: 283-288.

Gotmark, F., and M. Ahlund. 1984. Do field observers attract nest predators and influence nesting success of common eiders? Journal of Wildlife Management 48: 381387.

Goudie, R. I., G. J. Robertson, and A. Reed. 2000. Common eider (Somateria mollissima). Number 546. In The Birds of North America. Edited by A. Poole and F. Gill. The Birds of North America, Inc., Philadelphia, Pennsylvania.

Hipfner, J. M., H. G. Gilchrist, A. J. Gaston, and D. K. Cairns. 2002. Status of Common Eiders, Somateria mollissima, nesting in the Digges Sound region, Nunavut. Canadian Field-Naturalist 116: 22-25.

Lack, D. 1933. Nesting conditions as a factor controlling breeding time in birds. Proceedings of the Zoological Society of London 104: 231-237.

Laursen, K., and J. Frikke. 2008. Hunting from motorboats displaces Wadden Sea eiders Somateria mollissima from their favoured feeding distribution. Wildlife Biology 14: 423-433.

Laursen, K., J. Frikke, and J. Kahlert. 2008. Accuracy of 'total counts' of waterbirds from aircraft in coastal waters. Wildlife Biology 14: 165-175.

Lock, A. R. 1986. A census of Common Eiders breeding in Labrador and the Maritime provinces. Pages 30-38 in Eider ducks in Canada. Edited by A. Reed. Canadian Wildlife Service Report Series Number 47.

Lopoukhine, N., N. A. Prout, and H. E. Hirvonen. 1978. The ecological land classification of Labrador. Ecological Land Classification Series 4. Environment Canada, Ottawa.

Mawhinney, K., A. W. Diamond, P. Kehoe, and N. Benjamin. 1999. Status and productivity of Common Eiders in relation to the status of Great Black-backed Gulls and Herring Gulls in the southern Bay of Fundy and northern Gulf of Maine. Waterbirds 22: 253-262.

Mendall, H. L. 1980. Intergradation of eastern North American eiders. Canadian Field-Naturalist 94: 286-292.

Merkel, F. R. 2004. Evidence of population decline in common eiders breeding in western Greenland. Arctic 57: 2736.

Nettleship, D. N., and P. G. H. Evans. 1985. Distribution and status of Atlantic Alcidae. Pages 53-154 in The Atlantic Alcidae. Edited by D. N. Nettleship and T. R. Birkhead. Academic Press, London.

Parker, H., and F. Mehlum. 1991. Influence of sea ice on nesting density in the common eider Somateria mollissima in Svalbard. Norsk Polarinstitutt Skrifter 195: 31-36.

Quinlan, S. E., and W. A. Lehnhausen. 1982. Arctic fox, Alopex lagopus, predation on nesting common eiders, Somateria mollissima, at Icy Cape, Alaska. Canadian FieldNaturalist 96: 462-466.

Rail, J-F., and R. Cotter. 2007. Sixteenth census of seabird populations in the sanctuaries of the North Shore of the Gulf of St. Lawrence, 2005. Canadian Field-Naturalist 121: 287-294.

Robertson, G. J., and H. G. Gilchrist. 1998. Evidence of population declines among common eiders breeding in the Belcher Islands, Northwest Territories. Arctic 51: 378-385.

Suydam, R. S., D. L. Dickson, J. B. Fadley, and L. T. Quakenbush. 2000. Population declines of King and Common Eiders of the Beaufort Sea. Condor 102: 219-222.

Weller, M. W. 1956. A simple field candler for waterfowl eggs. Journal of Wildlife Management 20: 111-113.

Received 19 May 2009

Accepted 9 June 2010 